\title{
OBSERVATION OF X-RAY ABSORPTION MAGNETIC CIRCULAR DICHROISM IN WELL-CHARACTERIZED IRON-COBALT-PLATINUM MULTILAYERS
}

\author{
A.F. JANKOWSKI \\ G.D. WADDILL \\ J.G. TOBN \\ This paper was prepared for submittal to the \\ Materials Research Society \\ San Francisco, CA \\ April 12-16, 1993
}

April 1993

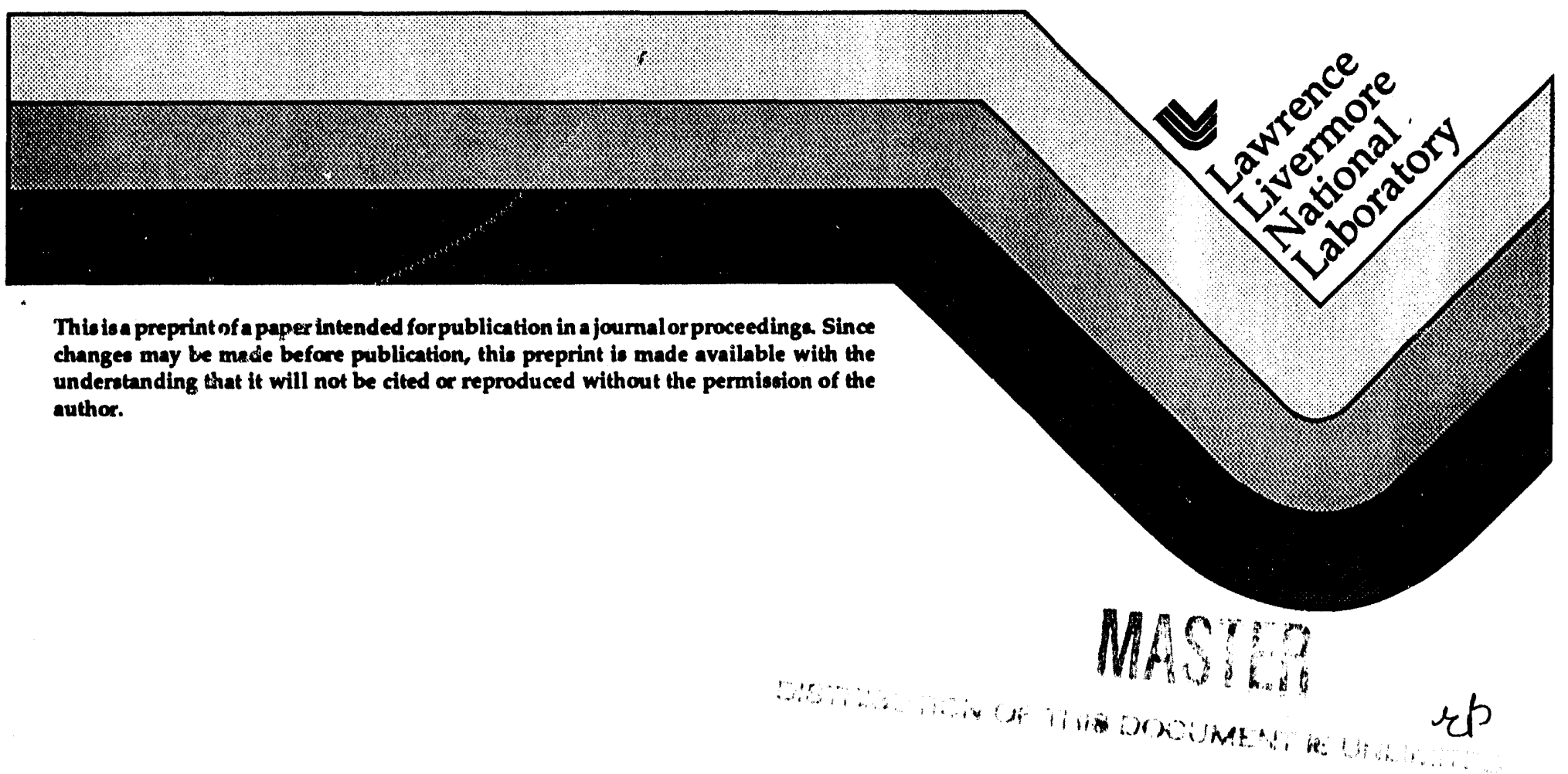




\section{DISCLAIMER}

This do:ument was prepared as an account of work sponsored by an agency of the United states Government. Neither the United States Government nor the University of California nor any of their employees, makes any warranty, express or implied, or assumes any legal liability or responsibility for the accuracy, completeness, or usefulness of any information, apparatus, product, or process disclosed, or represents that its use would not infringe privately owned rights. Reference herein to any specific commercial products, process, or service by trade name, trademark, manufacturer, or otherwise, does not necessarily constitute or imply its endorsement, recommendation, or favoring by the United States Government or the University of California. The views and opinions of authors expressed herein do not necessarily state or reflect those of the United States Government or the University of California, and shall not be used for advertising or product endorsement purposes. 


\title{
OBSER VATION OF X-RAY ABSORPTION MAGNETIC CIRCULAR DICHRUISM IN WELL-CHARACTERIZED IRON-COBALT-PLATINUM MULTILAYERS
}

A.F. JANKOWSKI, G.D. WADDILL and J.G. TOBIN

Lawrence Livermore National Laboratory, Chemistry \& Materials Science Department, P.O. Box 808, Livermore, California 94550 U.S.A.

\begin{abstract}
Magnetic circular dichroism in the Fe $2 \mathrm{p} \mathrm{x}$-ray absorption is observed in multilayers of $(\mathrm{Fe} 9.5 \AA / \mathrm{Pt} 9.5 \AA)_{92}$. The magnetization and helicity are both in the plane of this multilayer which is prepared by magnetron sputter deposition. This sample is part of a siudy to examine magnetization in the ternary multilayer system of $\mathrm{FeCo} / \mathrm{Pt}$. Lattice and layer pair spacings are measured using $x$-ray scattering. The atomic concentration profiles of the multilayer films are characterized using Auger electron spectroscopy coupled with depth profiling. Conventional and high resolution transmission electron microscopy are used to examine the thin film, growth morphology and atomic structure.
\end{abstract}

\section{INTRODUCTION}

The observation of perpendicular magnetic anisotropy in the $\mathrm{Co} / \mathrm{Pt}^{[1-4]}$ and $\mathrm{Fe} / \mathrm{Pt}^{[5]}$ multilayer systems proves to be of interest for magnetic recording applications. The magnetic properties of $\mathrm{Fe} / \mathrm{Pt}$ multilayer films are strongly dependent on the relative as well as absolute layer thicknesses.[6] X-ray absorption spectroscopy (XAS) is used for elemental analysis and magnetic -circular-dichroism (MCD)-measurements. It is shown that $\mathrm{MCD}$ can be a useful technique for monitoring changes in the orientation of sample magnetization. ${ }^{[7]}$ An in-plane magnetization of a $(\mathrm{Fe} 9.5 \AA / \mathrm{Pt} 9.5 \AA)_{92}$ multilayer thin film is found using both MCD and conventional magnetometry. ${ }^{[8]}$ The MCD technique has the potential to follow the magnetic axis orientation in $\mathrm{FeCo} / \mathrm{Pt}$ magnetic thin films as well as provide elemental specific determination of the magnetic moment.

\section{SAMPLE PREPARATION}

The $\mathrm{FeCo} / \mathrm{Pt}$ multilayer samples are prepared using magnetron sputter deposition. The deposition chamber is cryogenically pumped to a base pressure of $1.3 \times 10^{-5} \mathrm{~Pa}$. A circular array of magnetron sources is situated $20 \mathrm{~cm}$ beneath an oxygen-free copper platen. The magnetron sources are operated in the dc mode at a 330-390 Volt discharge. An argon working gas pressure of $0.40 \mathrm{~Pa}$ is used at a flow rate of $15.5 \mathrm{cc} \mathrm{min}-1$. The substrates are

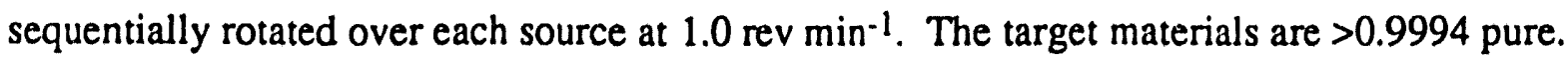
The polished Si substrates are cleaned with a procedure consisting of a detergent wash, 
deionized water rinse, alcohol rinse and a $\mathrm{N}_{2}$ gas drying prior to deposition. The substrates remain at a temperature between 293 and $306 \mathrm{~K}$ during the deposition. The sputter deposition rates, between 0.02 and $0.50 \mathrm{~nm} \mathrm{sec}-1$, are monitored using calibrated quartz crystals. The quartz crystals indicate the component layer thicknesses (Sample column of Table I) and the layer pair thicknesses, $\mathrm{d}_{\mathrm{FeC}} / \mathrm{Pt}_{\mathrm{PTC}}$. The multilayer films are grown to a $0.2 \mu \mathrm{m}$ thickness.

\section{CHARACTERIZATION METHODS AND RESULTS}

\section{X-Ray Diffraction}

The lattice and layer pair spacings of the $\mathrm{FeCo} / \mathrm{Pt}$ multilayers are measured using $\mathrm{x}$-ray diffraction. A powder diffractometer equipped with a graphite monochromator is operated in the $\theta / 2 \theta$ mode at both grazing incidence and high angle using $\mathrm{Cu} K \alpha$ radiation. The grazing incidence scans of the multilayer films (XRD column of Figs.1a-f) reveal the satellite reflections about $(000)$ attributable to the composition modulation in the multilayer growth direction. The first three satellite peak positions $(n=1,2,3)$ are corrected for refraction and fitted to compute a layer pair spacing $d_{F e C o / P t} X R D$ (Table I). The layer pair spacings $\mathrm{d}_{\mathrm{FeCO} / \mathrm{Pt}} \mathrm{XRD}$ are in agreement to within $0.01 \mathrm{~nm}$ of the crystal monitor values $\mathrm{d}_{\mathrm{FeCO}} / \mathrm{Pt}^{\mathrm{XTC}}$. The high angle Bragg reflections indicate that the thin film samples are all oriented along the [111] direction of a face-centered-cubic ( $f(c)$ lattice. The interplanar spacing, $d_{(111)}$ XRD (Table 1$)$, is generally intermediate to the values of pure $\mathrm{Pt}(111)$ at $0.2266 \mathrm{~nm}$ and $\gamma \mathrm{Fe}(111)$ at $0.2106 \mathrm{~nm}$. A first-order satellite reflection below the Bragg reflection in the $\theta / 2 \theta$ scans indicates layer pair spacings, from the relationship [ $\left.s(111)^{-s_{\text {satellite }}}\right]^{-1}$ where $s=d^{-1}$, for the films consistent with the grazing incidence measurements. [6]

Table I. - Layer Pair and-Interplanar-fpacings (nm) of $\mathrm{FeCo} / \mathrm{Pt}(111)$ Multilayers

\begin{tabular}{|c|c|c|c|}
\hline Sample & $\mathrm{d}(111)^{\mathrm{XRD}}$ & $\mathrm{d} F e C o / \mathrm{Pt}^{\mathrm{XRD}}$ & $\mathrm{d}_{\mathrm{FeCo} / \mathrm{Pt}^{\mathrm{XTC}}}$ \\
\hline$(\mathrm{Co3.9A} / \mathrm{Pt} 9.1 \AA)_{135}$ & 0.2223 & 1.295 & 1.294 \\
\hline$(\mathrm{Fe} 1.7 \AA \mathrm{Col} .8 \AA / \mathrm{Pt} 9.7 \AA)_{135}$ & 0.2246 & 1.288 & 1.313 \\
\hline$(\mathrm{Fe} 9.5 \AA / P+9.5 \AA) 92$ & 0.2193 & 2.008 & 1.895 \\
\hline$(\mathrm{Fe} 3.0 \AA / \mathrm{Pt} 9.7 \AA)_{135}$ & 0.2252 & 1.280 & 1.267 \\
\hline$(\mathrm{Fe} 3.1 \AA / \mathrm{Pt} 19.4 \AA)_{76}$ & 0.2270 & 2.228 & 2.245 \\
\hline$(\mathrm{Fe} 3.1 \AA / \mathrm{Pt} 38.8 \AA)_{44}$ & 0.2274 & 4.238 & 4.187 \\
\hline
\end{tabular}

\section{Auger Electron Spectroscopy}

Atomic concentration profiles of the multilayer thin films are measured using Auger electron spectroscopy (AES) coupled with depth profiling. A $3 \mathrm{keV}, 10 \mu \mathrm{A}$ electron beam is used to generate the Auger electrons. The measured intensities of the $1.967 \mathrm{keV}$ platinum peak (Pt MNN), the $703 \mathrm{eV}$ iron peak (Fe LMM), the $272 \mathrm{eV}$ carbon peak (C KLL) and the $503 \mathrm{eV}$ oxygen peak $(\mathrm{O} K L \mathrm{~L}$ ) from data accumulated in the derivative mode are used to compute the 

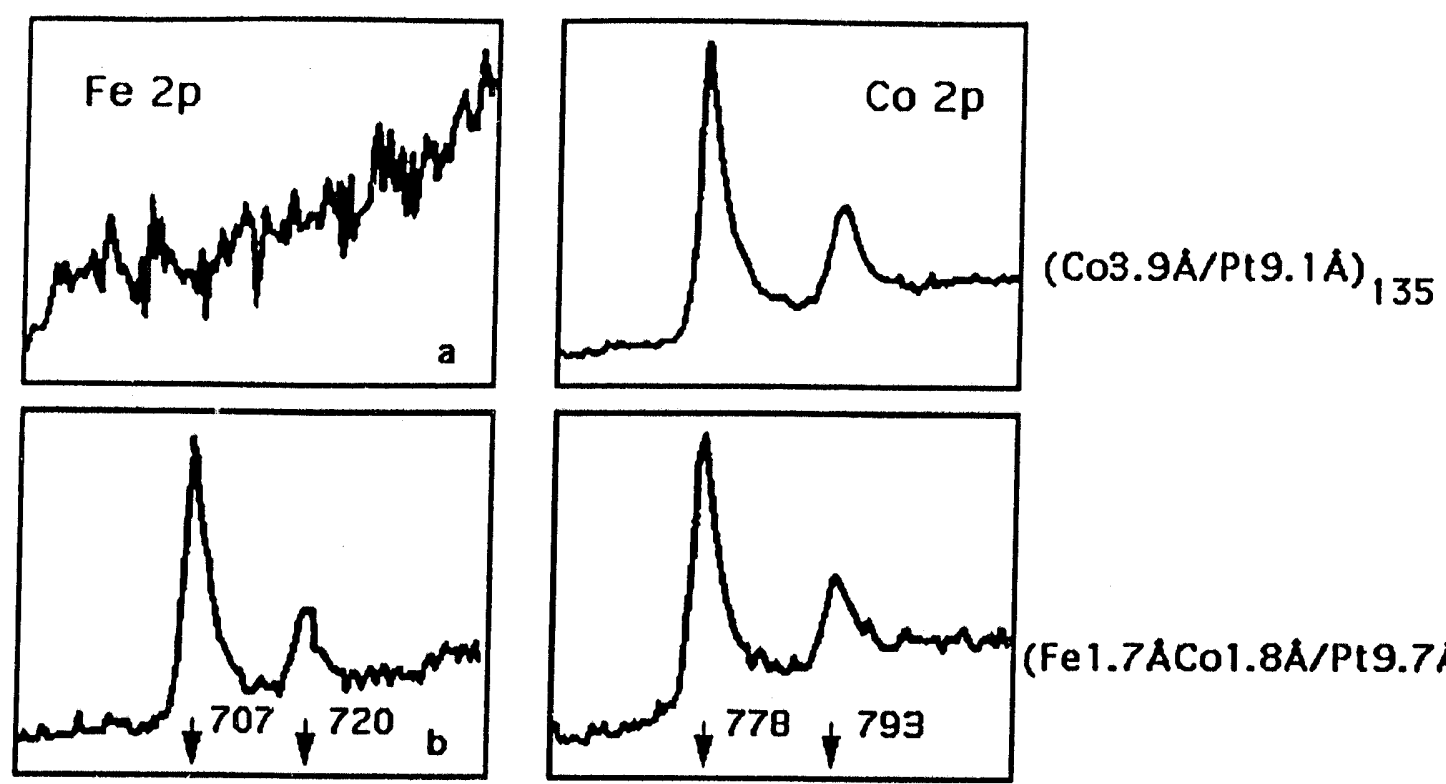

$\left(\mathrm{Fe} 1.7 \mathrm{ACo} 1.8 \mathrm{~A} / \mathrm{Pt}\right.$ 9.7A ${ }_{135}$
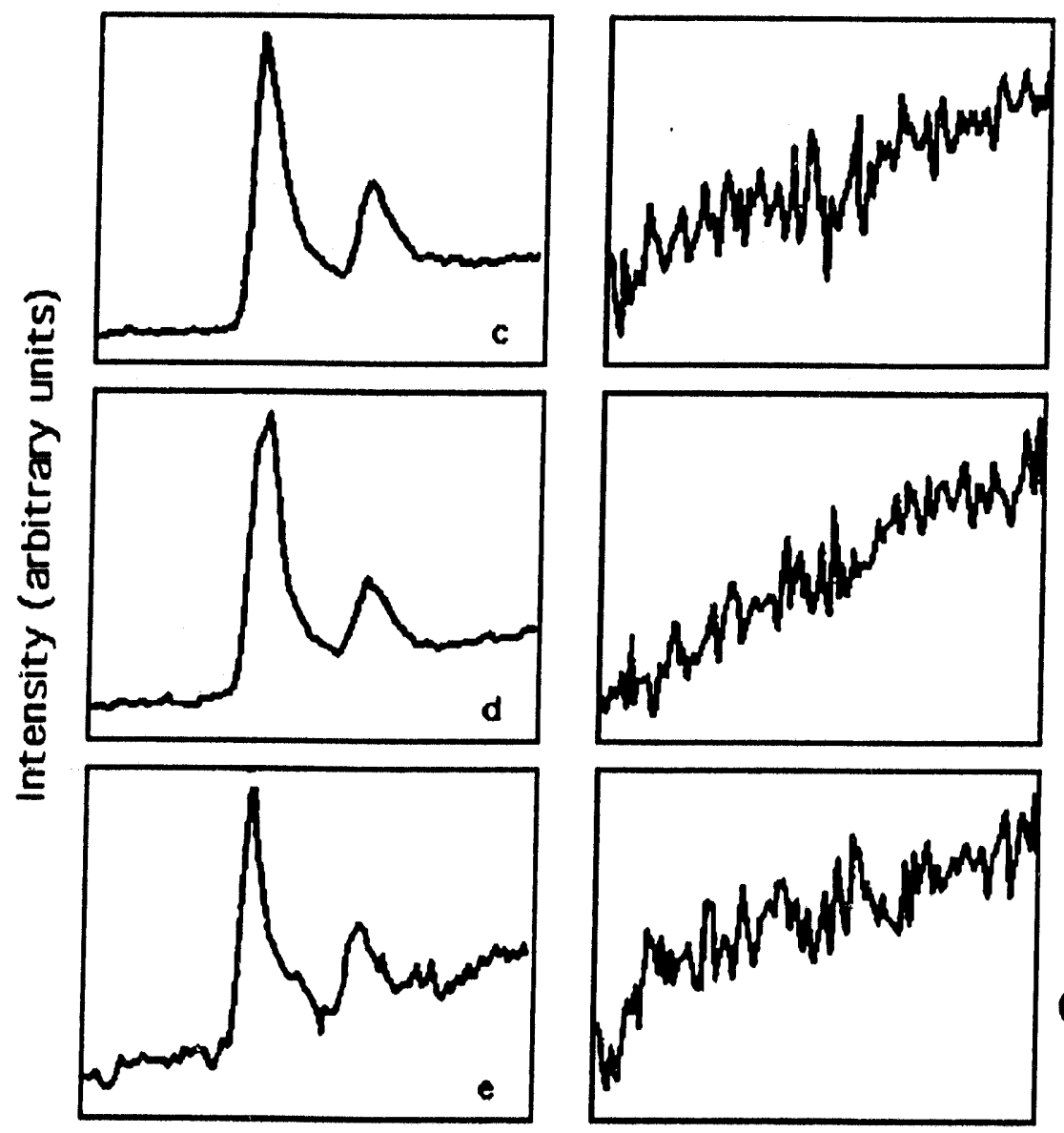

$\left.{ }^{(F e 9.5 A / P t 9.5 A)}\right)_{92}$

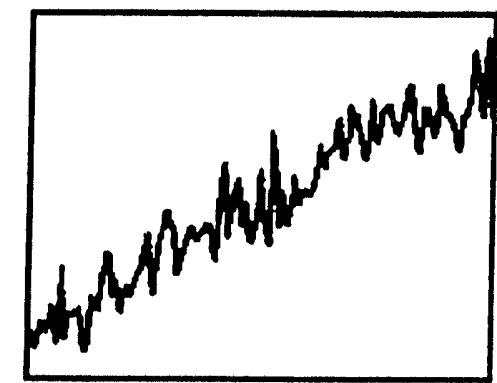

$($ Fe3.0A/Pt9.7A) 135

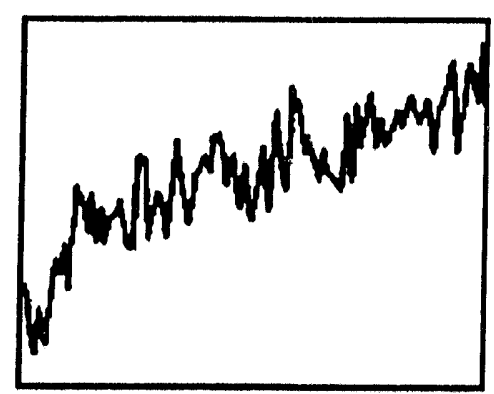

${ }^{(F e 3.1 A / P t ~ 19.4 A)}{ }_{76}$
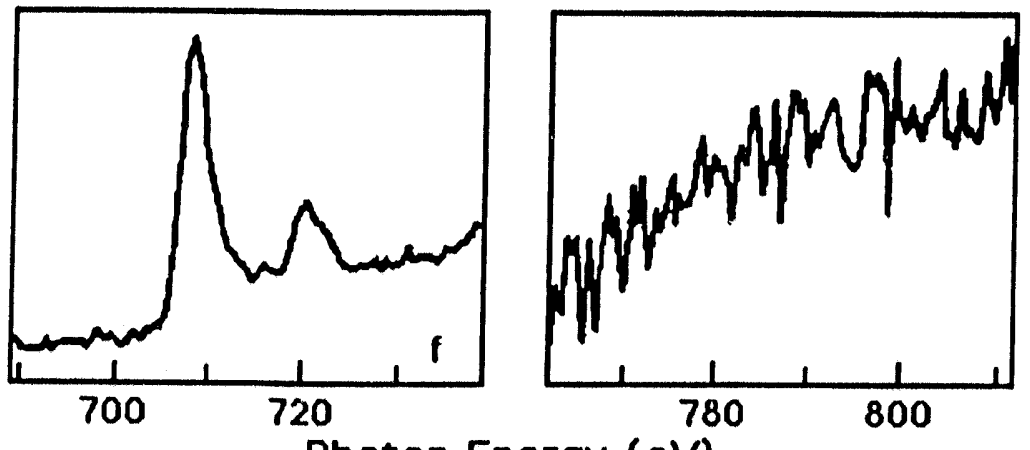

$(\mathrm{Fe} 3.1 \mathrm{~A} / \mathrm{P}+38.8 \mathrm{~A})_{44}$

Figure 1. The columns correspond to the $x$-ray absorption at the $F e 2 p$ and $C o 2 p$ edges using linear polarization and normal incidence measurement of the $\mathrm{FeCo} / \mathrm{Pt}$ multilayer samples. 

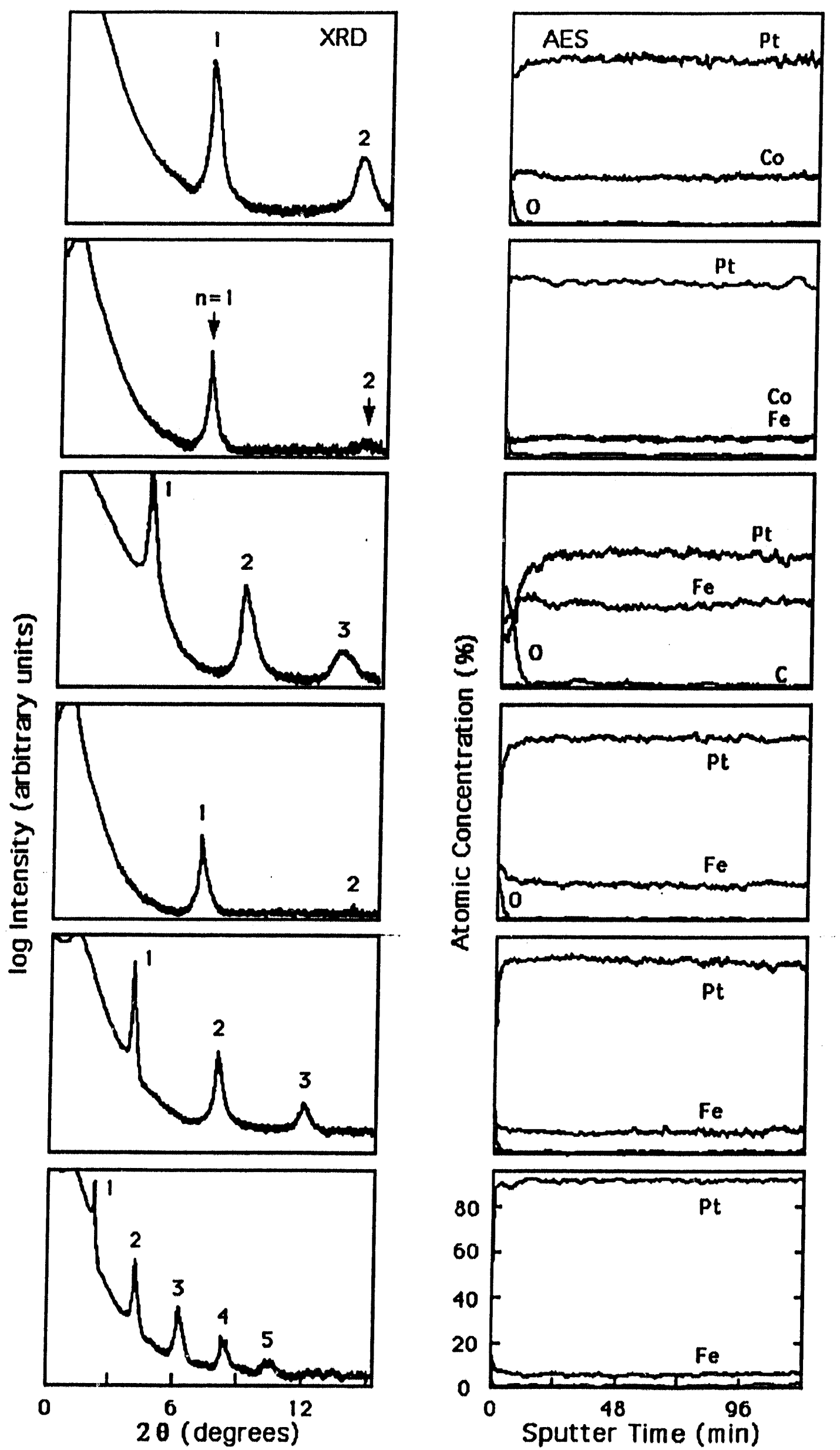

Figure 1.(continued) The columns correspond with grazing incidence $x$-ray diffraction (XRD) scans and Auger (AES) depth profiles of the $\mathrm{FeCo} / \mathrm{Pt}$ multilayer samples, as listed in (a-f). 
atomic concentrations. A $2 \mathrm{keV}, 0.92 \mu \mathrm{A}$ argon ion beam is used to sputter etch a $25 \mathrm{~mm}^{2}$ area of the sample surface. The gas pressure for the sputter etch is $4 \times 10^{-3} \mathrm{~Pa}$ whereas the Auger system base pressure is $6.7 \times 10^{-8} \mathrm{~Pa}$. Once the surface oxide is sputtered through, the film composition is shown to be uniform and free of any $\mathrm{C}$ or $\mathrm{O}$ contamination (AES column of Figs.1a-f). The concentration analysis of the films using AES are in agreement to within 10\% of the absolute concentration value for each component as determined from the calibrated quartz crystal monitor readings of component layer thicknesses.

\section{Transmission Electron Microscopy}

Transmission electron microscopy (TEM) and high resolution imaging reveal the multilayer film morphology and lattice structure. The $\mathrm{FeCo} / \mathrm{Pt}$ films, as imaged in both plan view (Fig.2a) and cross-section (Fig.2c), are typified by a dense columnar growth. The plan view electron diffraction patterns reveal the polycrystalline, in-plane nature of the films. The ring pattern (Fig. 2b) of this fcc phase is indexed to a lattice parameter of $0.3848 \mathrm{~nm}$. This lattice spacing corresponds quite well with the high angle diffraction data that gives a lattice parameter of $0.3798 \mathrm{~nm}$. Diffraction patterns, taken from the multilayer as viewed in cross-section, reveal a 5-8 mosaic of the lattice planes perpendicular to the [111] growth direction. Selected area diffraction patterns of individual grains, viewed in cross-section (Fig. 2d), clearly show the [111] growth direction of an fcc phase in this [110] pole projection. The FeCo/Pt thin film samples are therefore [111] textured in the growth direction but randomly oriented in-plane. The average grain size is $27-30 \mathrm{~nm}$, as measured from the bright field images (as Fig.2a). Lattice images, recorded at the Scherzer defocus condition using a $400 \mathrm{keV}$ electron beam, show each grain to consist of a single-phase fcc structure (Fig.3).

\section{X-ray Absorption Spectroscopy and Magnetic Circular Dichroism}

The XAS and MCD measurements are performed on a spherical grating monochromator with the ability to generate soft $X$-rays with a high degree of linear or circular polarization. $[9,10]$ The absorption measurements are made in a partial electron yield mode with a kinetic energy window centered around $50 \mathrm{eV}$. The XAS spectra (Fe $2 \mathrm{p}$ and $\mathrm{Co} 2 \mathrm{p}$ columns in Fig. 1a-f) are for normal incidence (i.e. $0^{\circ}$ from the sample normal). The curves correspond to linear polarization scans for elemental analysis. The presence of $\mathrm{Fe}$ as well as $\mathrm{Co}$ is detected for even

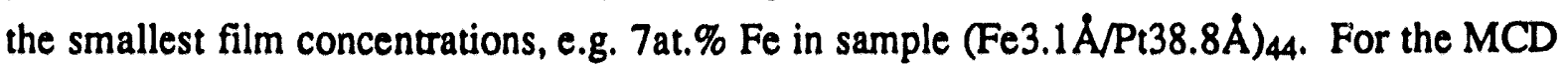
measurements, the samples are magnetized in-situ with a pulse coil capable of generating a $3 \mathrm{kOe}$ field. MCD in X-ray absorption is observed as a circular polarization dependent intensity variation in the $L_{2}$ and $L_{3}$ edges for $3 d$ transition metals. The polarization dependence requires that the incident $x$-ray helicity (either parallel or anti-parallel to the direction of propagation) be aligned or anti-aligned with the sample magnetization. $[7,11]$ The polarization dependence vanishes when these vectors are perpendicular. An intensity difference for the $L_{2}$ and $L_{3}$ white lines is apparent for sample (Fe9.5 $/ \mathrm{Pt}+5 \AA)_{92}$ demonstrating a remnant, in-plane magnetization of the film (Fig.4).

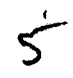




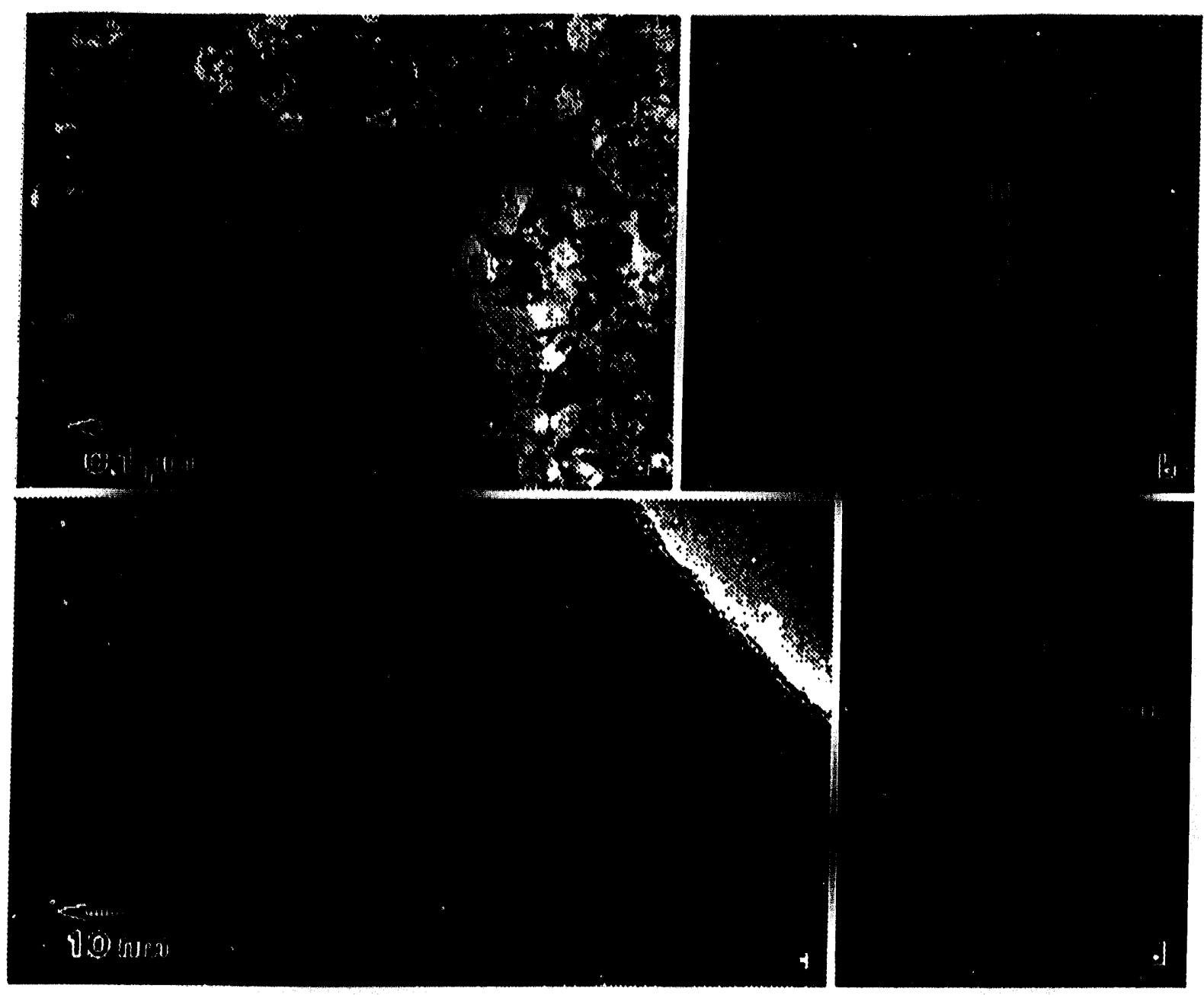

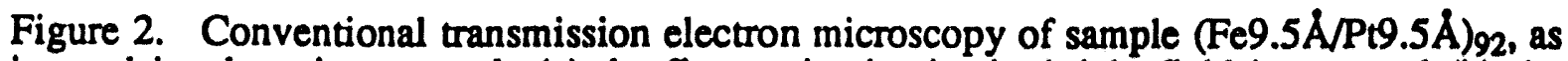
imaged in plan view, reveals (a) the fine grain size in the bright field image and (b) the preferred (111), texture in the electron diffraction pattern of the film. Imaging of sample

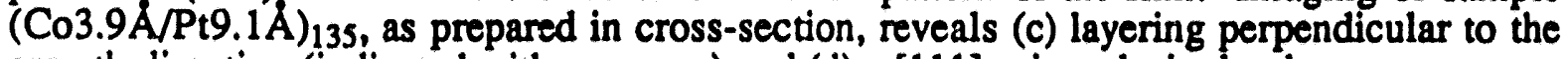
growth direction (indicated with an arrow) and (d) a [111] oriented, single-phase structure as seen in the [110] pole projection of this face-centered cubic, selected area diffraction pattern.

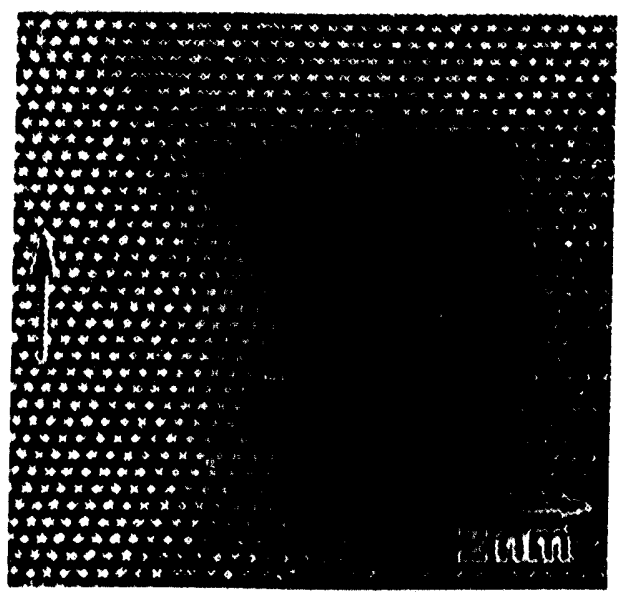

Figure 3. High resolution electron micrograph of the sample (Fe9.5 $/ \mathrm{Pt} 9.5 \AA)_{92}$, as imaged in cross-section. The growth direction is indicated with an arrow.

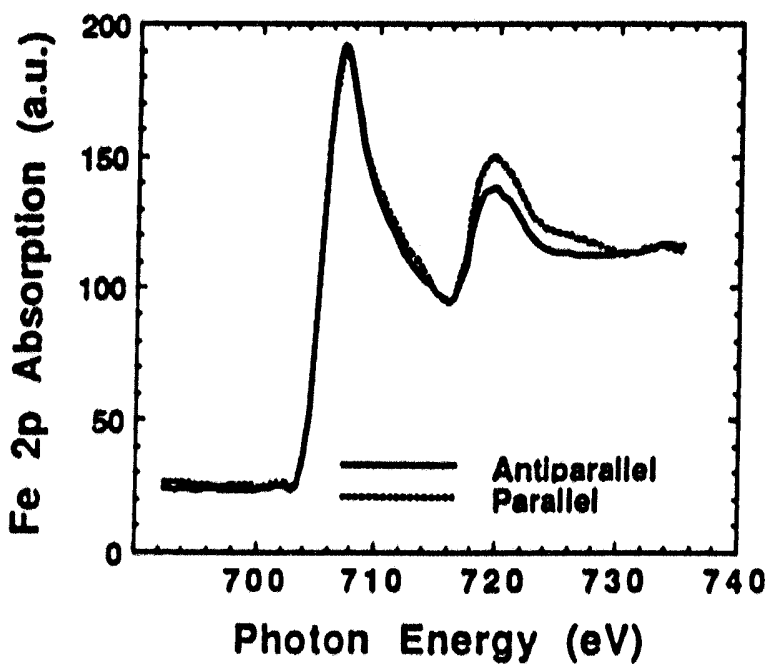

Figure 4. Fe L-edge absorption spectra of the (Fe9.5A/P $9.5 \AA)_{92}$ multilayer for the $x$-ray helicity and majority d-electron spin nearly parallel (-.-) and antiparallel (-). This is an illustration of magnetic circular dichroism using circularly polarized $x$-rays. 


\section{DISCUSSION \& SUMMARY}

The relative strengths of the $L_{2}$ and $L_{3}$ absorption edges contain information about the spindependent density of states near the Fermi level and the spin-orbit splitting in the d-bands. Therefore, information is available about the spin and orbital magnetic moments of the material. $[7,12-14]$ The spin moment analysis $[7]$ applied to sample (Fe9.5 $\AA / \mathrm{P} 19.5 \AA)_{92}$ yields a value of $1 \pm 0.5 \mu_{\mathrm{B}} / \mathrm{Fe}$. The analysis is complicated, however, by the polycrystalline surface. If the sample is not of a single domain, then MCD will average the domains yielding a moment that reflects the average projection of magnetization along the photon propagation direction.

In summary, we have studied the microstructure of $\mathrm{FeCo} / \mathrm{Pt}$ multilayer films using $\mathrm{x}$-ray diffraction and transmission electron microscopy, the composition using $\mathbf{x}$-ray absorption and Auger spectroscopy, and the magnetic behavior using MCD. The correlation of structural properties with magnetic anisotropy requires detailed and elemental sensitive characterization. $\mathrm{MCD}$ enables the study of multi-element films, as $\mathrm{FeCo} / \mathrm{Pt}$, where the local moments can be determined for each component material:

\section{ACKNOWLEDGMENTS}

The MCD measurements were performed at the Stanford Synchrotron Radiation Laboratory. We thank Mark Wall for the transmission electron microscopy images. This work was performed under the auspices of the United States Department of Energy by Lawrence Livermore National Laboratory under sontract W-7405-Eng-48.

\section{REFERENCES}

1 P.F. Carcia, A.D. Meinhaldt and A. Suna, Appl. Phys. 47, 178 (1985).

2 P.F. Carcia, J. Appl. Phys. 63, 5066 (1988).

3 Z. Zhang, P.E. Wigen and S.S.P. Parkin, J. Appl. Phys. 69, 5649 (1991).

4 B.D. Hermsmeier, R.F.C. Farrow, C.H. Lee, E.E. Marinero, C.J. Lin, R.F. Marks and C.J. Chien, J. Appl. Phys. 69, 5646 (1991).

5 T. Katayama, Y. Suzuki,Y. Nishihara, T. Sugimoto and M. Hashimoto, J. Appl. Phys. 69, 5658 (1991).

6 E. Devlin, V. Psycharis, A. Kostikas, A. Simopoulos, D. Niarchos, A. Jankowski, T. Tsakalakos, H. Wan and G. Hadjipanayis, J. Magn. Magn. Mater., in press (1993).

7 J.G. Tobin, G.D. Waddill and D.P. Pappas, Phys. Rev. Lett. 68, 3642 (1992).

8 A.F. Jankowski, G.D. Waddill and J.G.Tobin, Bull. Amer. Phys. Soc. 38 (1), 831 (1993).

9 K.G. Tirsell and V. Karpenko, Nucl. Instrum. Meth. A 291, 511 (1990).

10 L.J. Terminello, G.D. Waddill and J.G. Tobin, Nucl. Instrum. Meth. A 319, 271 (1992).

11 J.L. Erskine and E.A. Stern, Phys. Rev. B 12, 5016 (1975).

12 B.T. Thole and G. van der Laan, Phys. Rev.A 38, 1943 (1988); B 42, 6670 (1990).

13 B.T. Thole, P. Carra, F. Sette and G. vander Laan, Phys. Rev. Lett. 68, 1943 (1992).

14 P. Carra, B.T. Thols, M. Altarelli and X. Wang, Phys. Rev. Lett. 70, 694 (1993). 

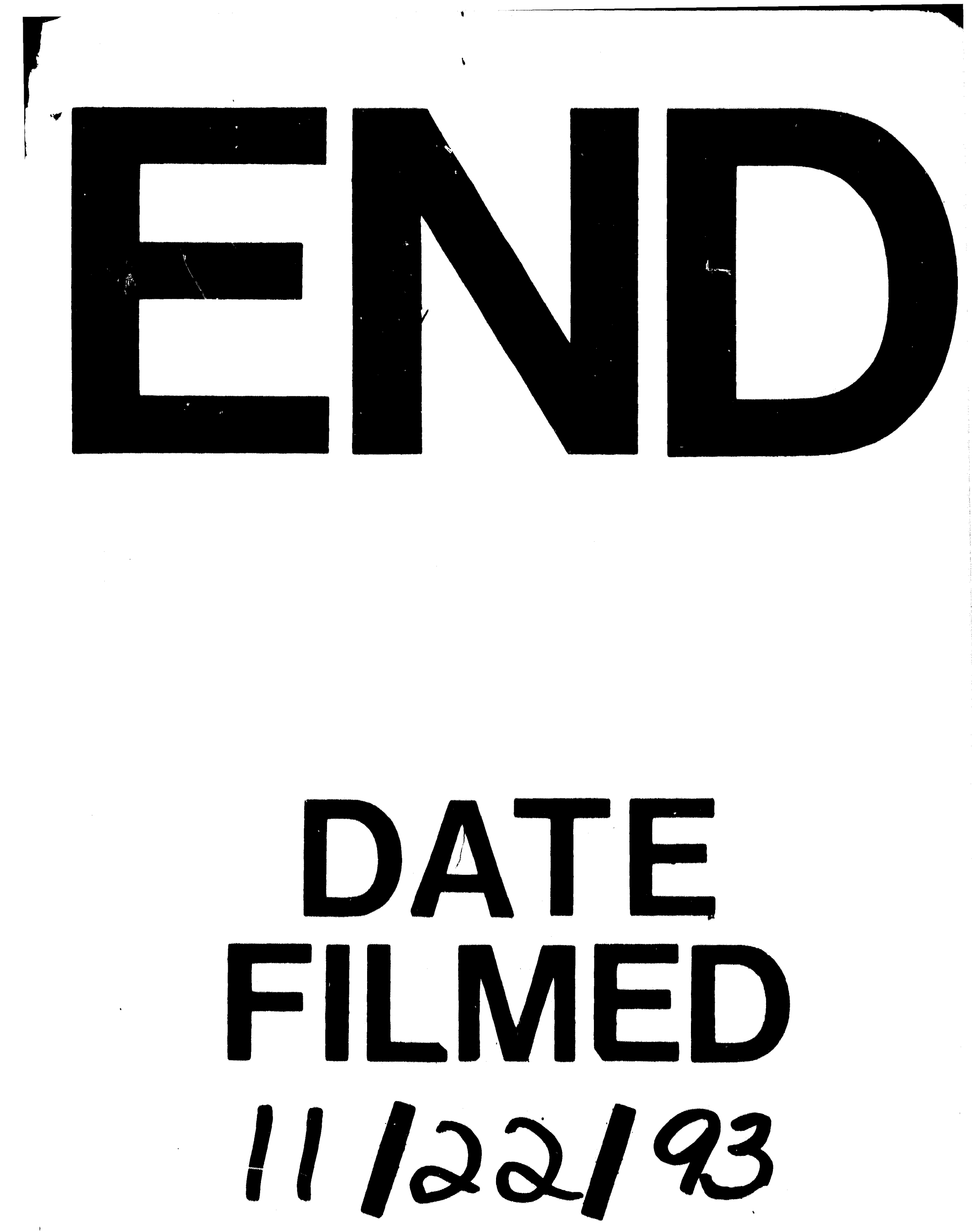


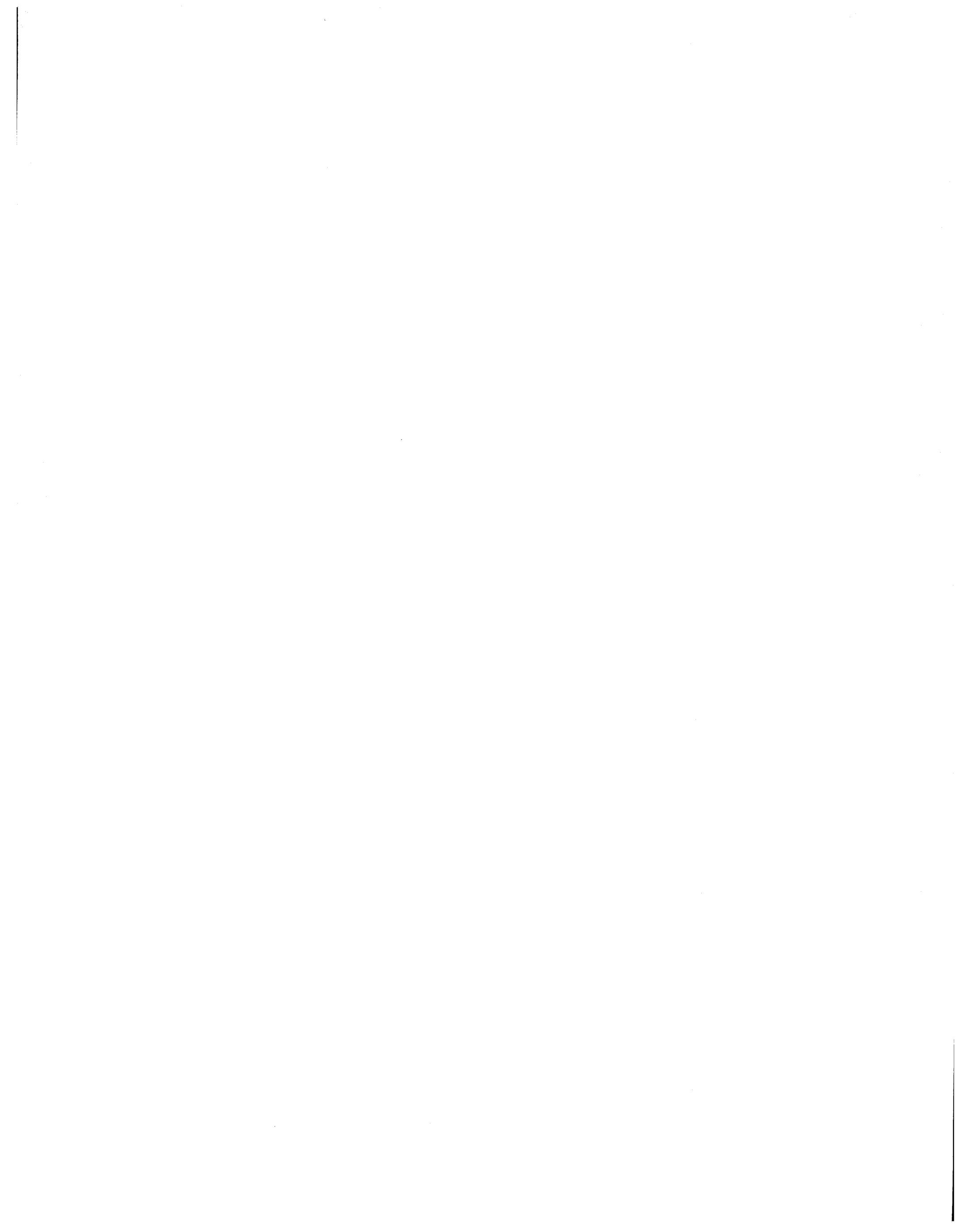

